\title{
The effect of low-dose combined hormone therapy (oestradiol and norethindrone acetate) on serum (-reactive protein levels and life quality in natural menopause women
}

\author{
Servin Gocer ${ }^{1}$, Suleyman Guven ${ }^{2}$, Hidayet Sal${ }^{2}$, Emine Seda Guvendag Guven ${ }^{2}$ \\ 1Department of Obstetrics and Gynaecology, Okan University School of Medicine, Istanbul, Turkey \\ ${ }^{2}$ Department of Obstetrics and Gynaecology, Karadeniz Technical University School of Medicine, Trabzon, Turkey
}

\begin{abstract}
Introduction: To assess the effect of low-dose combined oestradiol and norethindrone acetate hormone therapy (HT) on serum C-reactive protein (CRP) levels and life quality in natural menopause women.

Material and methods: Forty-five natural menopause women admitted to the clinic during a 1-year period and diagnosed as menopause, who planned to have HT for menopausal symptoms, were enrolled in this prospective study. The serum CRP levels were measured, and vasomotor symptoms scores were graded according to the Blatt-Kupperman menopause index, and life quality scores according to the Menopause-Specific Quality of Life Questionnaire (MENQOL) were recorded before and after (3 months later) hormone therapy.

Results: The Blatt-Kupperman menopause index and MENQOL scores were significantly decreased after 3 months of low-dose treatment. No significant difference was found between white blood cell counts and serum CRP levels before and after 3 months of hormone therapy.

Conclusions: Considering all HT types and biochemical effects, low-dose HT, which had positive results in terms of quality of life, was a safe treatment and could be preferred to conventional-dose preparations in cases without contraindications. Low-dose combined HT containing oestradiol and norethindrone acetate did not alter the serum CRP level in postmenopausal cases.
\end{abstract}

Key words: Blatt-Kupperman index, CRP, oestradiol, Menopause-Specific Quality of Life Questionnaire (MENQOL), norethindrone acetate.

\section{Introduction}

Quality of life $(\mathrm{QOL})$ is a condition that reflects the patient's feel and function. The most common symptoms in menopausal women are vasomotor symptoms, and the main reason for this is menopause, which determines the QOL. Vasomotor symptoms and hot flashes are the most common symptom of women in menopause, which are present in $50-85 \%$ of women in menopause [1].

Hormone therapy (HT) is used to improve climacteric symptoms and to achieve physical-psychosocial development. Today, many studies and opinions argue that the use of HT improves the health QOL, which means that the individual is in good health in terms of both physical and psychosexual functions [2]. The term low-dose HT refers to the lowest effective use dose of $\mathrm{HT}$, which is a regimen containing lower amounts of oestrogen than the conventional dose. However, there is insufficient literature information about the effect of low-dose HT on QOL. The continuous regimen of lowdose HT containing $1 \mathrm{mg} 17 \beta$-oestradiol + $0.5 \mathrm{mg}$ nore- thindrone acetate (E2 + NETA) was first introduced in 1990. Lower doses of HT reduce the incidence of possible hormone-mediated side effects (such as chest pain and bleeding) and maintain positive treatment effects $[3,4]$. Risks such as venous thromboembolism (VTE) and stroke are minimal in low-dose regimens [5]. While menopausal symptoms are reduced with high doses of oestrogen, the incidence of side effects such as VTE, cerebrovascular accident, bleeding, and stroke also increases [6, 7]. The treatment should continuous and have lower dose hormone regimen in order to decrease these undesired side effects and risks [8, 9]. A recent study also reported that continuous combined $\mathrm{HT}$ was associated with higher risk of breast cancer than a cyclical regimen [10].

Hormone therapy creates a risk of cardiovascular disease by affecting the inflammation and haemostasis process. Results of studies regarding the effect of HT on the increase of C-reactive protein (CRP), which is an inflammatory marker that can be considered as a risk factor for cardiovascular disease, should be discussed [11]. Hormone therapy affected the serum

Corresponding author:

Prof. Suleyman Guven, Department of Obstetrics and Gynaecology, Karadeniz Technical University School

Submitted: 02.08.2021

of Medicine, Trabzon, Turkey, e-mail: drsuleymanguven@yahoo.com

Accepted: 27.08 .2021 
CRP concentration [12]. Oral HT increased the level of CRP [13]. Studies on the effect of low-dose HT on CRP have also been limited. The effect of low-dose continuous combined HT on the markers of vascular inflammation may be similar to that of other HT combinations [14]. The primary purpose of the study was to determine the effect of low-dose combined oestradiol and norethindrone acetate on menopausal symptoms and QOL and the frequency of early side effects in natural menopausal cases. The secondary aim of the study was to investigate the effect of low-dose HT on the CRP in these natural menopausal cases.

\section{Material and methods}

\section{Individuals}

In this prospective cohort study, a total of 45 natural menopausal cases who were diagnosed as menopause and planned for menopausal symptoms in a period of 1 year were included in this study. The number and date of approval of the Scientific Research Ethics Committee of current faculty was 2007/25 and 29.06.2007, respectively.

\section{Patient selection}

A total of 110 cases whose HT was planned due to menopausal symptoms in the menopause unit of our clinic were evaluated in terms of admission and non-acceptance criteria.

Criteria for admission to the research were as follows:

- agreeing to consent,

- postmenopausal women between 45 and 55 years old, - not having had menstruation for the past 6 months,

Table 1. Blatt-Kupperman index

\begin{tabular}{lccc}
\hline Symptoms & $\begin{array}{c}\text { Example } \\
\text { Factor }\end{array}$ & Severity & $\begin{array}{c}\text { Numerical } \\
\text { conversion } \\
\text { factor X severity }\end{array}$ \\
\hline Vasomotor & 4 & $M$ & 8 \\
\hline Paraesthesia & 2 & + & 6 \\
\hline Insomnia & 2 & + & 6 \\
\hline Nervousness & 2 & $\mathrm{M}$ & 4 \\
\hline $\begin{array}{l}\text { Melancholia } \\
\text { (depression) }\end{array}$ & 1 & + & 3 \\
\hline Vertigo & 1 & $\mathrm{~S}$ & 1 \\
\hline Weakness (fatigue) & 1 & $\mathrm{~S}$ & 1 \\
\hline Arthralgia & 1 & $\mathrm{M}$ & 2 \\
and myalgia & 1 & $\mathrm{~S}$ & 1 \\
\hline Headaches & 1 & + & 3 \\
\hline Palpitations & 1 & 0 & 35 \\
\hline Formication & & & \\
\hline Menopausal index & & & \\
\hline - none, & & & \\
\hline
\end{tabular}

0 - none, $\mathrm{S}$ - slight, $\mathrm{M}$ - moderate, +- severe
- hormone results compatible with menopause (FSH $>20 \mathrm{mlU} / \mathrm{ml}, \mathrm{E} 2<20 \mathrm{mlU} / \mathrm{ml}$ ) and presence of vasomotor and/or menopausal symptoms (moderate to severe),

- no systemic disease (diabetes mellitus [DM], HT, hyperlipidaemia, ischaemic heart disease) or infectious disease in the past 2 weeks,

- not taking any HT or medication for at least 2 months,

- no contraindications for HT in routine menopause evaluation,

- willingness to take $\mathrm{HT}$,

- no smoking.

Criteria for exclusion from the study were as follows:

- having any systemic disease (DM, HT, hyperlipidaemia, ischaemic heart disease) $(n=12)$,

- smoking ( $n=13$, in addition, 9 cases had a history of both systemic disease and smoking),

- contraindications for HT ( $n=11$ cases had undetermined vaginal bleeding),

- failure to attend follow-up $(n=8)$,

- inability to complete 3 months of HT $(n=9)$,

- stopping HT due to vaginal bleeding during HT $(n=12)$.

Cases meeting the inclusion criteria were evaluated within the scope of this prospective cohort study. The results of routine tests (general physical examination, breast examination, pelvic exam, cervicovaginal smear, complete blood count, hormone levels [FSH, E2, TSH], liver-kidney function tests, transvaginal ultrasonography, mammography, bone mineral densitometer) were determined to be appropriate in terms of HT in each case. Five cubic centimetres of blood were taken in a heparinized biochemistry tube in the morning at around 08.00-09.00 after 8 hours of fasting in order to study the CRP in blood serum. On the same day, a vasomotor symptom severity rating was made according to the Blatt-Kupperman index (Table 1). In the Blatt-Kupperman index evaluation, the severity of the symptoms reported to the patient was evaluated as absent (Coefficient 0), mild (Coefficient 1), moderate (Coefficient 2), and severe (Coefficient 3).

Quality of life evaluation was done by the Menopause-Specific Quality of Life Questionnaire (MENQOL) (Table 2) [15]. Vasomotor symptoms were evaluated as mild, moderate, and severe and were calculated in the Blatt-Kupperman index evaluation. The patients were asked to rank their symptoms from 0 to 6 in the MENQOL.

Blood was drawn for basal CRP. The patients who were evaluated for the Blatt-Kupperman index and MENQOL were prescribed to take 3 months of hormone treatment, which included $1.03 \mathrm{mg}$ of oestradiol hemihydrate and $0.5 \mathrm{mg}$ of norethindrone acetate (Activelle ${ }^{\circledR}$, 1 tablet daily, Novo Nordisk, İstanbul). Activelle was chosen because it was the only commercially available continuous low-dose HT preparation in our country during the years of the study.

The patients who completed the 3-month continuous hormone treatment were seen again (within 10 days). 
Table 2. Menopause-Specific Quality of Life Questionnaire

\begin{tabular}{|c|c|c|c|c|c|c|c|c|c|}
\hline \multirow[t]{2}{*}{ Hot flashes } & $\square$ & $\square$ & $\square$ & $\square$ & $\square$ & $\square$ & $\square$ & $\square$ & $\square$ \\
\hline & no & yes & 0 & 1 & 2 & 3 & 4 & 5 & 6 \\
\hline \multirow[t]{2}{*}{ Night sweats } & $\square$ & $\square$ & $\square$ & $\square$ & $\square$ & $\square$ & $\square$ & $\square$ & $\square$ \\
\hline & no & yes & 0 & 1 & 2 & 3 & 4 & 5 & 6 \\
\hline \multirow[t]{2}{*}{ Sweating } & $\square$ & $\square$ & $\square$ & $\square$ & $\square$ & $\square$ & $\square$ & $\square$ & $\square$ \\
\hline & no & yes & 0 & 1 & 2 & 3 & 4 & 5 & 6 \\
\hline \multicolumn{10}{|l|}{ Psychosocial symptoms } \\
\hline \multirow[t]{2}{*}{ Being dissatisfied with my personal life } & $\square$ & $\square$ & $\square$ & $\square$ & $\square$ & $\square$ & $\square$ & $\square$ & $\square$ \\
\hline & no & yes & 0 & 1 & 2 & 3 & 4 & 5 & 6 \\
\hline \multirow[t]{2}{*}{ Feeling anxious or nervous } & $\square$ & $\square$ & $\square$ & $\square$ & $\square$ & $\square$ & $\square$ & $\square$ & $\square$ \\
\hline & no & yes & 0 & 1 & 2 & 3 & 4 & 5 & 6 \\
\hline \multirow[t]{2}{*}{ Experiencing poor memory } & $\square$ & $\square$ & $\square$ & $\square$ & $\square$ & $\square$ & $\square$ & $\square$ & $\square$ \\
\hline & no & yes & 0 & 1 & 2 & 3 & 4 & 5 & 6 \\
\hline \multirow[t]{2}{*}{ Accomplishing less than I am used to } & $\square$ & $\square$ & $\square$ & $\square$ & $\square$ & $\square$ & $\square$ & $\square$ & $\square$ \\
\hline & no & yes & 0 & 1 & 2 & 3 & 4 & 5 & 6 \\
\hline \multirow[t]{2}{*}{ Feeling depressed, down, or blue } & $\square$ & $\square$ & $\square$ & $\square$ & $\square$ & $\square$ & $\square$ & $\square$ & $\square$ \\
\hline & no & yes & 0 & 1 & 2 & 3 & 4 & 5 & 6 \\
\hline \multirow[t]{2}{*}{ Being impatient with other people } & $\square$ & $\square$ & $\square$ & $\square$ & $\square$ & $\square$ & $\square$ & $\square$ & $\square$ \\
\hline & no & yes & 0 & 1 & 2 & 3 & 4 & 5 & 6 \\
\hline \multirow[t]{2}{*}{ Feelings of wanting to be alone } & $\square$ & $\square$ & $\square$ & $\square$ & $\square$ & $\square$ & $\square$ & $\square$ & $\square$ \\
\hline & no & yes & 0 & 1 & 2 & 3 & 4 & 5 & 6 \\
\hline \multicolumn{10}{|l|}{ Physical symptoms } \\
\hline \multirow[t]{2}{*}{ Flatulence or gas pains } & $\square$ & $\square$ & $\square$ & $\square$ & $\square$ & $\square$ & $\square$ & $\square$ & $\square$ \\
\hline & No & Yes & 0 & 1 & 2 & 3 & 4 & 5 & 6 \\
\hline \multirow[t]{2}{*}{ Aches in the muscles and joints } & $\square$ & $\square$ & $\square$ & $\square$ & $\square$ & $\square$ & $\square$ & $\square$ & $\square$ \\
\hline & No & Yes & 0 & 1 & 2 & 3 & 4 & 5 & 6 \\
\hline \multirow[t]{2}{*}{ Feeling tired or worn out } & $\square$ & $\square$ & $\square$ & $\square$ & $\square$ & $\square$ & $\square$ & $\square$ & $\square$ \\
\hline & No & Yes & 0 & 1 & 2 & 3 & 4 & 5 & 6 \\
\hline \multirow[t]{2}{*}{ Difficulty sleeping } & $\square$ & $\square$ & $\square$ & $\square$ & $\square$ & $\square$ & $\square$ & $\square$ & $\square$ \\
\hline & No & Yes & 0 & 1 & 2 & 3 & 4 & 5 & 6 \\
\hline \multirow[t]{2}{*}{ Aches in the back, neck, or head } & $\square$ & $\square$ & $\square$ & $\square$ & $\square$ & $\square$ & $\square$ & $\square$ & $\square$ \\
\hline & No & Yes & 0 & 1 & 2 & 3 & 4 & 5 & 6 \\
\hline \multirow[t]{2}{*}{ Decrease in physical strength } & $\square$ & $\square$ & $\square$ & $\square$ & $\square$ & $\square$ & $\square$ & $\square$ & $\square$ \\
\hline & No & Yes & 0 & 1 & 2 & 3 & 4 & 5 & 6 \\
\hline \multirow[t]{2}{*}{ Decrease in stamina } & $\square$ & $\square$ & $\square$ & $\square$ & $\square$ & $\square$ & $\square$ & $\square$ & $\square$ \\
\hline & No & Yes & 0 & 1 & 2 & 3 & 4 & 5 & 6 \\
\hline \multirow[t]{2}{*}{ Feeling a lack of energy } & $\square$ & $\square$ & $\square$ & $\square$ & $\square$ & $\square$ & $\square$ & $\square$ & $\square$ \\
\hline & No & Yes & 0 & 1 & 2 & 3 & 4 & 5 & 6 \\
\hline \multirow[t]{2}{*}{ Dry skin } & $\square$ & $\square$ & $\square$ & $\square$ & $\square$ & $\square$ & $\square$ & $\square$ & $\square$ \\
\hline & No & Yes & 0 & 1 & 2 & 3 & 4 & 5 & 6 \\
\hline Weight gain & $\square$ & $\square$ & $\square$ & $\square$ & $\square$ & $\square$ & $\square$ & $\square$ & $\square$ \\
\hline & No & Yes & 0 & 1 & 2 & 3 & 4 & 5 & 6 \\
\hline Increased facial hair & $\square$ & $\square$ & $\square$ & $\square$ & $\square$ & $\square$ & $\square$ & $\square$ & $\square$ \\
\hline & No & Yes & 0 & 1 & 2 & 3 & 4 & 5 & 6 \\
\hline Changes in appearance, texture, or tone of skin & $\square$ & $\square$ & $\square$ & $\square$ & $\square$ & $\square$ & $\square$ & $\square$ & $\square$ \\
\hline & No & Yes & 0 & 1 & 2 & 3 & 4 & 5 & 6 \\
\hline
\end{tabular}


Table 2. Cont.

\begin{tabular}{|c|c|c|c|c|c|c|c|c|c|}
\hline \multirow[t]{2}{*}{ Feeling bloated } & $\square$ & $\square$ & $\square$ & $\square$ & $\square$ & $\square$ & $\square$ & $\square$ & $\square$ \\
\hline & No & Yes & 0 & 1 & 2 & 3 & 4 & 5 & 6 \\
\hline \multirow[t]{2}{*}{ Low backache } & $\square$ & $\square$ & $\square$ & $\square$ & $\square$ & $\square$ & $\square$ & $\square$ & $\square$ \\
\hline & No & Yes & 0 & 1 & 2 & 3 & 4 & 5 & 6 \\
\hline \multirow[t]{2}{*}{ Frequent urination } & $\square$ & $\square$ & & $\square$ & $\square$ & $\square$ & $\square$ & $\square$ & $\square$ \\
\hline & No & Yes & 0 & 1 & 2 & 3 & 4 & 5 & 6 \\
\hline \multirow[t]{2}{*}{ Involuntary urination when laughing or coughing } & $\square$ & $\square$ & $\square$ & $\square$ & $\square$ & $\square$ & $\square$ & $\square$ & $\square$ \\
\hline & No & Yes & 0 & 1 & 2 & 3 & 4 & 5 & 6 \\
\hline \multirow[t]{2}{*}{ Breast tenderness } & $\square$ & $\square$ & $\square$ & $\square$ & $\square$ & $\square$ & $\square$ & $\square$ & $\square$ \\
\hline & No & Yes & 0 & 1 & 2 & 3 & 4 & 5 & 6 \\
\hline \multirow[t]{2}{*}{ Vaginal bleeding } & $\square$ & $\square$ & $\square$ & $\square$ & $\square$ & $\square$ & $\square$ & $\square$ & $\square$ \\
\hline & No & Yes & 0 & 1 & 2 & 3 & 4 & 5 & 6 \\
\hline \multirow[t]{2}{*}{ Leg pain } & $\square$ & $\square$ & $\square$ & $\square$ & $\square$ & $\square$ & $\square$ & $\square$ & $\square$ \\
\hline & No & Yes & 0 & 1 & 2 & 3 & 4 & 5 & 6 \\
\hline \multicolumn{10}{|l|}{ Sexual symptoms } \\
\hline \multirow[t]{2}{*}{ Avoiding intimacy } & $\square$ & $\square$ & 0 & $\square$ & $\square$ & $\square$ & 4 & $\square$ & $\square$ \\
\hline & No & Yes & $\square$ & 1 & 2 & 3 & $\square$ & 5 & 6 \\
\hline \multirow[t]{2}{*}{ Vaginal dryness during intima } & $\square$ & $\square$ & 0 & $\square$ & $\square$ & $\square$ & 4 & $\square$ & $\square$ \\
\hline & No & Yes & & 1 & 2 & 3 & $\square$ & 5 & 6 \\
\hline
\end{tabular}

Five cubic centimetres of blood were taken again for study. On the same day, the vasomotor symptom severity rating was evaluated according to the Blatt-Kupperman index, and the QOL was evaluated according to the menopause - private quality of life questionnaire.

\section{Statistical analysis}

All data were entered by coding in the SPSS 10.0 package program. Student's $t$-test, $\chi^{2}$ test, and $U$ Mann-Whitney test were used for comparison. $P$-value $<0.05$ was considered statistically significant.

According to our preliminary study result, it was assumed that the average Blatt-Kupperman menopause index (BKMI) value decreased from 29 to 15 with hormone therapy. The standard deviation was determined as 10. It was calculated that total of 45 patients would achieve a $99.99 \%$ power of detection of differences at a significance level $(\alpha)$ of 0.05 , using a 2-sided t-test (matched pairs).

\section{Results}

The general clinical and laboratory features of the patients who were given low-dose HT due to vasomotor symptoms were given in Table 3. Although one of the inclusion criterion was absence of menstruation for 6 months, all cases had at least 12 months of amenorrhoea.

The comparison of the total Blatt-Kupperman index (Fig. 1) and MENQOL (Fig. 2) according to the pre-treat- ment status in the study group is given in the graphs. According to these figures, the total BKMI decreased from $29.35 \pm 10.24$ to $15.93 \pm 7.63$ after 3 months of low-dose HT $(p<0.001)$. Similarly, the total MENQOL score decreased from $67.69 \pm 23.93$ to $38.89 \pm 18.06$ after 3 months of low-dose HT $(p<0.001)$.

The Menopause-Specific Quality of Life Questionnaire total vasomotor, psychosocial, and physical symptom scores decreased statistically significantly after 3 months of low-dose hormone therapy. However, no statistically significant decrease was found in terms of sexual symptom scores.

There was no statistically significant difference between the levels of white blood cells (6915 \pm 2444 vs. $7139 \pm 1869$ numbers $/ \mathrm{ml}, p=0.535$ ) before and after treatment in the study group. Similarly, there was no statistically significant change in serum CRP levels (0.3278 \pm 0.2164 vs. $0.3140 \pm 0.2103 \mathrm{mg} / \mathrm{dl}, p=0.708)$ after 3 months of low-dose hormone therapy.

The only 8 cases during the 3-month low-dose HT (17.8\%) treatment complained of vaginal bleeding for several days in a spotting style. No pathological findings were detected in the pelvic examination, transvaginal ultrasonography, and endometrial biopsy in these cases. Vaginal hysterectomy was performed in 1 case (2.2\%) due to persistent bleeding after 3 months of treatment and additional symptoms and signs of pelvic organ prolapse. Also, in 1 case (2.2\%) a cyst was detected in the breast in the 3rd month after the treatment. After the evaluation, although the cyst was shown to be benign, the patient discontinued hormone therapy. 


\section{Discussion}

The health management of the women in menopause should not be limited to the treatment of biological changes; improving the QOL should be the main goal. Hormone therapy is used in many patients in the world to prevent symptoms such as sweating, anxiety, insomnia, loss of concentration, osteoporosis-related fractures, and loss of libido. Today, many studies argue that the use of HT improves the QOL, which means that the individual is in good health in terms of both physical and psychosexual functions. It was reported that women who do not receive HT experience more problems in their daily life activities and that anxiety increases by $40 \%$, sexual problems by $52 \%$, and vasomotor symptoms are seen 2 times more often in this patient group [2].

There is little information about the effect of lowdose HT on QOL. Norethindrone acetate and ethinyl oestradiol have an effect on vasomotor symptoms in postmenopausal women. Symptoms are reduced in postmenopausal women who constantly use HT. Response to treatment has been associated with dose to provide a minimally effective dose with different dose combinations [16]. Marked improvement in menopausal symptoms was noted in postmenopausal women with a uterus at an average age of 49 years, despite the use of low-dose HT (1 mg E2 hemihydrate $+0.5 \mathrm{mg}$ NETA), in the current study.

Generally, for women who are perimenopausal or in early postmenopause, continuous administration of $17 \beta$-oestradiol and cyclic administration of oral micronized progesterone was preferred. Eighty to ninety per cent of women receiving cyclic combined hormone regimens have monthly withdrawal bleeding [17]. Although the bleeding is often light, any menstrual bleeding is eventually bothersome for most postmenopausal women, and it is a common reason for discontinuation of therapy.

Quality of live is due not only to biological changes because of oestrogen deficiency but also to socioeconomic, cultural, and personal factors. Menopause causes different symptoms in people of the same or different cultures, and it has been reported that menopausal symptoms may be affected depending on cultural effects, physical causes, and individuals. Situations that negatively affect MENQOL are job status and having more children, and less education [18]. In the current study, the symptoms were evaluated more comprehensively with the Blatt-Kupperman index and MENQOL scoring, and $82 \%$ of women with menopausal symptoms were primary school graduates and $84 \%$ were housewives.

Hot flashes occur in $75 \%$ of menopausal women in the United States [19]. Hot flashes in many women who do not receive treatment will disappear on their own
Table 3. General clinical and laboratory features belonging to the research group

\begin{tabular}{|c|c|}
\hline Total number of cases & 45 \\
\hline Age (years) & $49.09 \pm 3.18(45-55)$ \\
\hline Weight (kg) & $61.94 \pm 6.11(50-72)$ \\
\hline Body mass index $\left(\mathrm{kg} / \mathrm{m}^{2}\right)$ & $24.78 \pm 2.26(21-30)$ \\
\hline Gravida (no) & $4.62 \pm 2.19(0-10)$ \\
\hline Parity (no) & $3.11 \pm 1.23(0-5)$ \\
\hline Abortion (no) & $0.71 \pm 0.84(0-3)$ \\
\hline Living (no) & $3.00 \pm 1.36(0-5)$ \\
\hline Average menopause time (years) & $2.33 \pm 2.05(1-8)$ \\
\hline \multicolumn{2}{|l|}{ Application complaint (\%) } \\
\hline Flushing & $31(68.9)$ \\
\hline Vaginal dryness + flushing & $4(8.9)$ \\
\hline Irritability + flushing & $3(6.6)$ \\
\hline Sleep disturbance + flushing & $2(4.4)$ \\
\hline Urinary complaints + flushing & $5(11.0)$ \\
\hline \multicolumn{2}{|l|}{ Educational status (\%) } \\
\hline No & $3(6.7)$ \\
\hline Primary school & $37(82.2)$ \\
\hline Middle school & $1(2.2)$ \\
\hline High school & $3(6.7)$ \\
\hline University & $1(2.2)$ \\
\hline \multicolumn{2}{|l|}{ Job (\%) } \\
\hline Housewife & $38(84.4)$ \\
\hline Teacher & $1(2.2)$ \\
\hline Official & $4(8.9)$ \\
\hline Other (technician etc.) & $2(4.4)$ \\
\hline \multicolumn{2}{|l|}{ Laboratory findings } \\
\hline Serum FSH (mIU/ml) & $46.72 \pm 23.00(21-90)$ \\
\hline Serum LH (mIU/ml) & $29.00 \pm 18.97(13-74)$ \\
\hline Serum E2 (pg/ml) & $13.60 \pm 3.00(8-19)$ \\
\hline $\begin{array}{l}\text { Number of white blood cells } \\
\text { (number/ml) }\end{array}$ & $6792 \pm 1588(3900-9900)$ \\
\hline CRP level (mg/dl) & $0.328 \pm 0.216(0.04-1.00)$ \\
\hline
\end{tabular}

Means \pm standard deviation is given as minimum and maximum values in parentheses or number of cases and percentages in parentheses.

within a few years [20]. Hot flash treatment is equally effective in the conjugated oestrogen and $17 \beta$-oestradiol regimen in the Women's Health Initiative and Heart and Oestrogen/progestin Replacement Study [21]. The main hormone affecting the QOL in postmenopausal women who have hot flashes from vasomotor symptoms is oestrogen [22]. Hot flashes decreased when the hormone therapy was started in this study.

In menopause, sexual desire decreases, the number of sexual intercourses and orgasms decreases, vaginal dryness increases, and therefore pain during sexual intercourse is high [23]. According to the results of the Women's Health Initiative, which is one of the largest 
series of studies on the effectiveness of HT in menopause, oestrogen treatment given with or without progesterone in menopause does not have a positive effect on sexual symptoms [24]. Likewise, no improvement in sexual symptoms was achieved after treatment in the current study. However, the reason for the lack of improvement in sexual symptoms may be the presence of low-dose oestrogen in HT or the result of short-term treatment (3 months).

Depression and mood improved with oestrogen therapy in women with and without climacteric symptoms in menopause [25]. The reduction of symptom scores in the current study supported this literature finding.

Intermenstrual bleeding that occurs in patients receiving a continuous hormone treatment protocol may cause discontinuation of the treatment [26]. Treatment is abandoned due to reasons such as vaginal bleeding, fear of breast and uterine cancer, tenderness in the breast, fatigue, and weight gain. Bleeding irregularity is minimal at the beginning of treatment with low-dose oestrogen. There were cases in NETA that interrupted the treatment due to intermenstrual bleeding [27]. In the current study, vaginal bleeding was observed in 8 cases, and a breast cyst was observed in 1 case. Although no abnormal pathology was found in the evaluations, the patients did not continue treatment.

Based on limited literature findings, continuous combinations of oestradiol valerate + levonorgestrel and oestradiol valerate + NETA increased CRP concentrations. Although these concentrations increased during the oestrogen phase, they remained constant with progestin intake [28]. The serum CRP level was less affected by low-dose HT due to its direct effect on gene order due to the first-pass effect with oral oestrogen intake $[29,30]$. In the current study, no significant difference was observed in CRP and white blood cell evaluation with low-dose HT use.

Although it was accepted in our research that a minimum of 45 cases were required to obtain statistically significant results within the scope of BKMI, there is a need for thousands of case studies in order for this type of HT to be widely recommended all over the world.

The most important limitation point of the current study was the low number of cases; a larger series to support the results of the study is needed. In our study, a preparation containing norethindrone acetate was used as progesterone. Knowing whether other progesterone preparations will have a similar effect is only possible with comparative research planning. This was the other limiting aspect of the research.

\section{Conclusions}

Considering all HT types and biochemical effects, low-dose $\mathrm{HT}$, which had positive results in terms of QOL, was a safe treatment and could be preferred to conventional-dose preparations in cases without contraindications. Low-dose combined HT containing oestradiol and norethindrone acetate did not alter the serum CRP level in postmenopausal cases.

\section{Disclosure}

The authors report no conflict of interest.

\section{References}

1. Kronenberg F. Hot flashes: epidemiology and physiologya. Ann N Y Acad Sci 1990; 592: 52-86

2. Genazzani A, Nicolucci A, Campagnoli C, et al. Assessment of the QoL in Italian menopausal women: comparison between HRT users and non-users. Maturitas 2002; 42: 267-280.

3. Coope J, Marsh J. Can we improve compliance with long-term HRT? Maturitas 1992; 15: 151-158.

4. Utian WH, Schiff I. NAMS-gallup survey on women's knowledge, information sources, and attitudes to menopause and hormone replacement therapy. Menopause 2018; 25: 1172-1179.

5. Hemelaar M, Kenemans P, Schalkwijk C, Braat D, van der Mooren M. No increase in C-reactive protein levels during intranasal compared to oral hormone therapy in healthy post-menopausal women. Hum Reprod 2006; 21: 1635-1642.

6. Vinogradova Y, Coupland C, Hippisley-Cox J. Use of hormone replacement therapy and risk of venous thromboembolism: nested case-control studies using the QResearch and CPRD databases. BMJ 2019; 364 k4810.

7. Vinogradova Y, Coupland C, Mustafa M, Hippisley-Cox J. Protocol to assess risk of venous thromboembolism associated with use of hormone replacement therapy in real world settings: two nested case-control studies in primary care. Available from https://www.semanticscholar. org/paper/Protocol-to-assess-risk-of-venous-thromboembolism-Vinogradova-Coupland/32df9b35d84a425e8f1c517d2b014c6241cedc26.

8. 8. Nudy M, Chinchilli VM, Foy AJ. A systematic review and meta-regression analysis to examine the 'timing hypothesis' of hormone replacement therapy on mortality, coronary heart disease, and stroke. Int J Cardiol Heart Vasc 2019; 22: 123-131.

9. Panay N, Studd J. Progestogen intolerance and compliance with hormone replacement therapy in menopausal women. Hum Reprod Update 1997; 3: 159-171.

10. Brusselaers N, Tamimi RM, Konings P, Rosner B, Adami HO, Lagergren J. Different menopausal hormone regimens and risk of breast cancer. Ann Oncol 2018; 29: 1771-1776.

11. Rifai N, Buring JE, Lee I-M, Manson JE, Ridker PM. Is C-reactive protein specific for vascular disease in women? Ann Inter Med 2002; 136: 529-533.

12. Ridker PM, Cushman M, Stampfer MJ, Tracy RP, Hennekens CH. Inflammation, aspirin, and the risk of cardiovascular disease in apparently healthy men. N En J Med 1997; 336: 973-979.

13. Herrington DM, Klein KP. Effects of estrogen on thrombosis and inflammation. Rev Cardiovasc Med 2019; 3: 49-56.

14. Van Baal MW, Kenemans P, van der Mooren MJ, Kessel H, Emeis JJ, Stehouwer CD. Increased C-reactive protein levels during short-term hormone replacement therapy in healthy postmenopausal women. Thromb Haemost 1999; 81: 925-928.

15. Lewis JE, Hilditch JR, Wong CJ. Further psychometric property development of the Menopause-Specific Quality of Life questionnaire and development of a modified version, MENQOL-Intervention questionnaire. Maturitas 2005; 50: 209-221.

16. Speroff L, Symons J, Kempfert N, Rowan J, Investigators FS. The effect of varying low-dose combinations of Norethindrone acetate and ethinyl estradiol (femhrt ${ }^{\circledR}$ ) on the frequency and intensity of vasomotor symptoms. Menopause 2000; 7: 383-390.

17. Archer DF, Pickar JH, Bottiglioni F. Bleeding patterns in postmenopausal women taking continuous combined or sequential regimens of conju- 
gated estrogens with medroxyprogesterone acetate. Menopause Study Group. Obstet Gynecol 1994; 83: 686-92.

18. Von Mühlen DG, Kritz-Silverstein D, Barrett-Connor E. A communitybased study of menopause symptoms and estrogen replacement in older women. Maturitas 1995; 22: 71-78.

19. Gold EB, Colvin A, Avis N, et al. Longitudinal analysis of the association between vasomotor symptoms and race/ethnicity across the menopausal transition: study of women's health across the nation. Am J Public Health 2006; 96: 1226-1235.

20. Cotangco K, Class Q, Kothari R. The change of life: understanding knowledge and attitudes regarding menopause and hormone replacement therapy in cervical cancer survivors. Gynecol Oncol 2020; 156: e13-e14.

21. Mosca L, Collins P, Herrington DM, et al. Hormone replacement therapy and cardiovascular disease: a statement for healthcare professionals from the American Heart Association. Circulation 2001; 104: 499-503.

22. Li J, Luo M, Tang R, et al. Vasomotor symptoms in aging Chinese women: findings from a prospective cohort study. Climacteric 2020; 23: 46-52.

23. Dimakopoulou A, Jayasena CN, Alkaabi FM, et al. A systematic review of randomized controlled trials investigating the efficacy and safety of testosterone therapy for female sexual dysfunction in postmenopausal women. Clin Endocrinol (Oxf) 2019; 90: 391-414.

24. Hays J, Ockene JK, Brunner RL, et al. Effects of estrogen plus progestin on health-related quality of life. N Engl J Med 2003; 348: 1839-54.

25. Leonhardt $M$. Low mood and depressive symptoms during perimenopause - Should General Practitioners prescribe hormone replacement therapy or antidepressants as the first-line treatment? Post Reprod Health 2019; 25: 124-130.

26. Graziottin A. Strategies for effectively addressing women's concerns about the menopause and HRT. Maturitas 1999; 33: 15-23.

27. Pinkerton JV. Hormone therapy for postmenopausal women. N En J Med 2020; 382: 446-455.

28. Skouby SO, Gram J, Andersen LF, Sidelmann J, Petersen KR, Jespersen J. Hormone replacement therapy: estrogen and progestin effects on plasma C-reactive protein concentrations. Am J Obstet Gynecol 2002; 186: 969-977.

29. Vehkavaara S, Silveira A, Hakala-Ala-Pietilä T, et al. Effects of oral and transdermal estrogen replacement therapy on markers of coagulation, fibrinolysis, inflammation and serum lipids and lipoproteins in postmenopausal women. Thromb Haemost 2001; 85: 619-625.

30. Coyle D, Cranney A, Tugwell P. Economic evaluation of norethisterone acetate/ethinylestradiol (FemHRT ${ }^{\circledR}$ ) for women with menopausal symptoms. Pharmacoeconomics 2003; 21: 661-669. 